\title{
DEFINITIVAMENTE: EPILEPSIA NÃO É DOENÇA
}

\author{
MARCO AURÉLIO SMITH FILGUEIRAS *
}

RESUMO - O autor analisa alguns conceitos do passado que, infelizmente, ainda perduram nos dias atuais, sobre o epiléptico como um doente mental e como portador de graves distúrbios de conduta capaz do cometimento de crimes do mais alto requinte de perversidade. Comprova pelas afirmações de eminentes personalidades do mundo científico, que epilepsia nada tem a ver com doença mental, com violência e que não é conceito nosológico de doença.

PALAVRAS-CHAVE: epilepsia, aspectos psiquiátricos, aspectos nosológicos.

Befinitive: epilepsy is not a disease:

SUMARY = The authof analyses past coneepts which still hold good today : such eoneepts regard epilepsy as a mental disease and the: epileptic is usually taken as someone suffering from a severe mental disordef, tending to efiminal behaviour: The authof proves, taking inte aceount vafious statements from prominent personalities in the seientific world, that epilepsy is neithef ta mental disease nof a disease in its own sense, and that the epileptic has not an aggassive behaviouf:

KEY WORDS: epilepsy, psychiatric aspects, nosologic aspects.

EPILEPSIA (do grego EPI, de cima e LEPSEM, abater) significa algo que vem de cima e de surpresa abate a pessoa, algo que vem de fora e ataca subitamente 3. Em decorrência desse significado' e pelo caráter às vezes dramático da forma convulsiva, tornou-se campo fértil para o cultivo de mitos, tabus e preconceitos 13. Assim é que, há milênios, condena-se o casamento de epilépticos; há milênios, foge-se do epiléptico em crise com medo do «contágio»^; há séculos, relaciona-se a convulsão à «possessão demoníaca» ou à «influência de maus espíritos»i3. Há longos anos, acusa-se, o seu portador de condutopata e potencialmente violento, capaz do cometimento de crimes do mais alto requinte de crueldade 6 . Desde tempos imemoráveis, o epiléptico é segregado socialmente, tratado' como doente mental, terrivelmente discriminado e marginalizado nas ruas, nosi lares, nas escolas, no trabalho.

França 4 vem chamando a atenção neste particular, quando afirma que «quando se tenta rotular a epilepsia como doença mental, por pretensas modificaçóes da personalidade pelo que nos acode, cometem-se dois erros básicos: primeiro, pela insignificante incidência dessas modificações comportamentais associadas à epilepsia, depois, a própria expressão doença mental, por si mesma, já é um absurdo (...). Limitar a capacidade civil do epiléptico é colocá-lo numa classe inferior de homens, proibidos de desfrutar os mesmos direitos e privilégios dos outros (...). Sob o prisma penal, peca-se ao rotular o epiléptico como problema grave, quando afirmam ter o caráter e comportamento alterados, exacerbados em seus instintos e serem autores de crimes violentos, sanguinários, intempestivos e selvagens. Isso é falso (...). O fato dessa periculosidade começa a ser desmascarado e seus valores estatísticos atuais assinalam cifras bem elevadas para os casos em que essei estado nada tem a ver com o delito cometido». Não há evidência de que violência seja mais comum entre epilépticos que em não epilépticos, e nem é miais comum em pacientes com crises parciais complexas que em outros

* Professor Adjunto da Disciplina de Neurologia da Universidade Federal da Paraíba, Presidente do Capítulo Paraibano da Liga Brasileira de Epilepsia.

Dr. Marco Aurélio Smith Filgueiras - Av. Monteiro da Franca 1063, Manaira $\quad-58035 \quad$ João Pessoa PB. Brasil. 
tipos de crises. Violencia ictal é rara e, quando ocorre, usualmente toma a forma de «violencia resistiva», como resultado de restrição física no fim de uma crise, enquanto o paciente ainda está confuso. No início da crise, é extremamente rara, estereotipada e nunca em fonna de séries consecutivas de movimentos resolutos. «Durante o estado pós-ictal, o paciente pode estar bíistante perturbado, mesmo violento, dando origem ao velho conceito clínico de furor epiléptico. Entretanto, na prática, tais atividades violentas são incoordenadas e mal direcionadas, desse modo são facilmente controladas», afirmam Laidlaw e Richens 9. «Atos complexos de violência têm muito pouca probabilidade de serem de origem epiléptica e o uso da epilepsia como defesa contra acusações de crimes violentos é, quase sempre, injustificado», atesta Porter 15. O velho estigma vinculado à maioria dos epilépticos como sendo pessoas impulsivas, agressivas, encontra pouco suporte em estudos científicos», ecreveu Fenwick, em 1976 (citado por Trimble e Reynolds 20).

Epilepsia é errônea ou equivocadamente associada, frequentemente, com furor homicida (um assassino epiléptico), deficiência mental, tendências criminais e antissociabilidade, assegura Frumento 5. Marino Jr. 11 enfatiza: «Contrariamente à crendice geral, a epilepsia é causa rara de agressividade articulada à disfunção cerebral. Clinicamente, o ato agressivo de linhagem epiléptica é reconhecido pela sua estruturação frouxa, pelo caráter aleatório de seu alvo, pelo colorido confusional e pelas manifestações paralelas de natureza epiléptica inequívoca. Esses elementos permitem o diagnóstico diferencial com agressividade relacionada a: personalidades psicopáticas, psicoses agitadas (síndrome paranóide, mania e depressão endógenas), oligofrenias agitadas, uso de álcool e outras drogas psicotrópicas». Entretanto, apesar dessas afirmações categóricas, a psiquiatria forense insiste em diagnosticar autores de crimes monstruosos, que ultimamente vêm sendo tão divulgados pela imprensa, como portadores de «epilepsia condu topa tica». Um falso diagnóstico, criado pela medicina judiciária há quase um século e que nunca deveria ter existido e muito menos continuar a vigorar nos dias atuais.

O «monstro» existe sim; é o portador de Personalidade Psicopática Anética ou Moral Insanity 18, que é captaz do cometimento de delitos de inimaginável crueza, e mais, pode até esquecer que o cometeu. Então, por que culpar o epiléptico de um crime que não é de sua responsabilidade? Sim, ele não está inocentado de tudo, pode cometer um crime, mas como todo ser humano, sem relação com a crise epiléptica.

Há pouco mais de 30 anos, fruto de toda sorte de estudos, análises e da acirrada luta empreendida pela comunidade neurológica e, em especial, pelos epileptologistas, a epilepsia foi finalmente excluída da Classificação Internacional das Doenças Psiquiátricas 20.

Depois dessa importante conquista, a ciência se ocupou em comprovar que a epilepsia não é doença e, sim, um distúrbio, uma síndrome ou simplesmente um sintoma. Pupo 16, há cerca de duas décadas, garantiu: «Epilepsia não é uma moléstia, é uma síndrome, isto é, um conjunto de manifestações clínicas várias, que se apresentam em consequência de processos mórbidos cerebrais, também vários, inteiramente diversos, segundo consideremos os grupos etários dos pacientes».

Mathes 12 assegura que «epilepsia não é conceito nosológico de doença». Outras declarações pertinentes foram feitas por: Marino Jr.11, Jeavons e Aspinall 8, Porter 15, Shorvon 17, Goldsohn et al.7 e Niedermeyer 14, entre outros 19. Na última proposta para revisão da Classificação das Epilepsias e Síndromes Epilépticas de 1988/89, a Comissão de Classificação e Terminologia da International League Against Epilepsy, presidida por Roger, praticamente definiu esta questão referindo-se à epilepsia unicamente como distúrbio ou síndrome 2. Portanto, definitivamente, não tem mais sentido se conceituar epilepsia como uma doença neurológica crônica $\mathbf{1}$, como muitos ainda estão apregoando.

\section{REFERENCIAS}

1. Buchpigel CA, Cukert A, Hironata FH, Cerri GG, Magalhães AEA, Marino R Jr. Brain Spect in the pre-surgical evaluation of epileptic patients. Arq Neuro-Psiquiat (São Paulo) 1992, 50:37-42.

2. Comission of Classification and Terminology of the International League against Epilepsy. Proposal for revised Classification of Epilepsies and epileptic syndromes. Epilepsia 1989, 30:389-399.

3. Dicionário Enciclopédico de Medicina. Ed 3. Lisboa: Argoeditora.

4. França GV de. Medicina Legal. Ed 3. Rio de Janeiro: Guanabara Koogan, 1991.

5. Frumento G. Legislative aspects in Italy. European Conference on Epilepsy. In Epilepsy and Society: Realities and Prospects. Amsterdam: Excerpta Médica, 1988, r 243-247.

6. Garcia JA. Psicopatologia Forense. Ed 3. Rio de Janeiro: Forense, 1979. 
7. Goldsohn ES, Glaser GH, Goldberg MA. Epilepsias. In: Merritt Tratado de Neurologia. Rio de Janeiro: Guanabara Koogan, 1986, p 638-660.

8. Jeavons PM, Aspinall A. The Epilepsy Reference Book. London: Harper \& Row, 1985.

9. Laidlaw J, Richens A. A Textbook of Epilepsy. Edinburgh: Churchill Livingstone, 1976.

10. Lima DRA. Epilepsia e Civilização. III Simpósio Paranaense de Epilepsia, Curitiba, 12/ 14 junho 1986 (Abstr.).

11. Marino R Jr. Epilepsias. São Paulo: Sorvi er, 1983.

12. Mathes A. Epilepsie: Diagnostik and Therapie für Klinik and Praxis. Stuttgart: Georg Thieme, 1975

13. Mello GB de. Epilepsia: mito e realidade. III Simpósio Paranaense de Epilepsia. Curitiba, 12/14 junho 1986 (Abstr).

14. Niedermeyer E. The Epilepsies: Diagnosis and Management. Baltimore: Urban \&Schwarzenberg, 1990

15. Porter RJ. Epilepsy: 100 Elementary Principles. London: Saunders, 1984.

16. Pupo PP. Questões sobre Epilepsia. Ed 2. São Paulo: Instituto de Eíletroencefalografia, 1971.

17. Shorvon SD. Epilepsy, a General Practice Perspective. Basel: Ciba-Geigy, 1988.

18. Schneider K. Las Personalidades Psicopáticas. Ed 7, Madrid: Morata, 1974.

19. Suzuki J, Seino M, Fukuyama Y, Konai S. Art and Science of Epilepsy, Amsterdam Excerpta Médica, 1989.

20. Trimble MR, Reynolds EH. Epilepsy Behaviour and Cognitive Function. London: John Libbey \& Sons, 1988. 